\title{
Functional stabilization of an RNA recognition motif by a noncanonical $\mathrm{N}$-terminal expansion
}

\author{
CATHARINA NETTER, ${ }^{1}$ GERT WEBER, ${ }^{1,2}$ HEIKE BENECKE, ${ }^{3}$ and MARKUS C. WAHL ${ }^{1,2}$ \\ ${ }^{1}$ Max-Planck-Institut für Biophysikalische Chemie, D-37077 Göttingen, Germany \\ ${ }^{2}$ Freie Universität Berlin Fachbereich Biologie, Chemie, Pharmazie, Institut für Chemie und Biochemie, D-14195 Berlin, Germany \\ ${ }^{3}$ Ruhr-Universität Bochum, Lehrstuhl für Zellphysiologie, D-44780 Bochum, Germany
}

\begin{abstract}
RNA recognition motifs (RRMs) constitute versatile macromolecular interaction platforms. They are found in many components of spliceosomes, in which they mediate RNA and protein interactions by diverse molecular strategies. The human U11/U12-65K protein of the minor spliceosome employs a C-terminal RRM to bind hairpin III of the U12 small nuclear RNA (snRNA). This interaction comprises one side of a molecular bridge between the U11 and U12 small nuclear ribonucleoprotein particles (snRNPs) and is reminiscent of the binding of the N-terminal RRMs in the major spliceosomal U1A and U2B" proteins to hairpins in their cognate snRNAs. Here we show by mutagenesis and electrophoretic mobility shift assays that the $\beta$-sheet surface and a neighboring loop of 65K C-terminal RRM are involved in RNA binding, as previously seen in canonical RRMs like the N-terminal RRMs of the U1A and U2B" proteins. However, unlike U1A and U2B", some 30 residues N-terminal of the 65K C-terminal RRM core are additionally required for stable U12 snRNA binding. The crystal structure of the expanded 65K C-terminal RRM revealed that the $\mathrm{N}$-terminal tail adopts an $\alpha$-helical conformation and wraps around the protein toward the face opposite the RNA-binding platform. Point mutations in this part of the protein had only minor effects on RNA affinity. Removal of the $\mathrm{N}$-terminal extension significantly decreased the thermal stability of the 65K C-terminal RRM. These results demonstrate that the 65K C-terminal RRM is augmented by an N-terminal element that confers stability to the domain, and thereby facilitates stable RNA binding.
\end{abstract}

Keywords: crystal structure; RNA recognition motif (RRM); RNP motif; U11/U12-65K protein; U11/U12 di-snRNP; U1A protein; U2B" protein; X-ray crystallography

\section{INTRODUCTION}

Spliceosomes are multisubunit RNA-protein enzymes that catalyze pre-mRNA splicing, i.e., the removal of noncoding sequences (introns) from precursor messenger RNA (premRNA) and the concomitant ligation of coding regions (exons) (for review, see Burge et al. 1999). Unique among other large, composite enzymes, spliceosomes assemble only in the presence of a substrate. Spliceosome assembly entails the stepwise binding of uridine-rich small nuclear ribonucleoprotein particles (U snRNPs) and numerous non-snRNP splicing factors on a pre-mRNA. After initial buildup of a pre-catalytic particle, major compositional and

Reprint requests to: Markus C. Wahl, Max-Planck-Institut für Biophysikalische Chemie, AG Makromolekulare Röntgenkristallographie Am Faßberg 11, D-37077 Göttingen, Germany; and Freie Universität Berlin Fachbereich Biologie, Chemie, Pharmazie, Institut für Chemie und Biochemie, AG Strukturbiochemie, Takustraße 6, D-14195 Berlin, Germany; e-mail: mwahl@gwdg.de; fax: 49-30-838-56702.

Article published online ahead of print. Article and publication date are at http://www.rnajournal.org/cgi/doi/10.1261/rna.1359909. conformational rearrangements are required to bring about a catalytically activated spliceosome (for review, see Reed and Palandjian 1997; Burge et al. 1999; Brow 2002; Nilsen 2003; Will and Lührmann 2006). Thus, spliceosome function critically relies both on persistent as well as on transient interactions among its building blocks.

Two types of spliceosomes have been identified in higher eukaryotes (for review, see Burge et al. 1999; Will and Lührmann 2005): the U2-dependent (major) spliceosome and the U12-dependent (minor) spliceosome. The major spliceosome excises U2-type introns, which represent the vast majority of pre-mRNA introns. The minor spliceosome removes U12-type introns, which make up less than $1 \%$ of all noncoding sequences in humans (Burge et al. 1998; Levine and Durbin 2001). The two types of spliceosomes utilize different, but functionally analogous, snRNPs. The major spliceosomal U1, U2, and U4/U6 snRNPs are replaced, respectively, by the $\mathrm{U} 11, \mathrm{U} 12$, and $\mathrm{U} 4 \mathrm{atac} / \mathrm{U} 6 \mathrm{atac}$ snRNPs in the minor spliceosome. The U5 snRNP is common to both spliceosomes. 
The snRNPs are composed of a unique snRNA, a set of seven $\mathrm{Sm}$ or Sm-like (LSm) proteins, and a varying number of particle-specific proteins (for review, see Will and Lührmann 1997). Analogous major and minor spliceosomal snRNPs differ either with respect to their RNA components only (U4/U6 versus U4atac/U6atac) or with respect to both their snRNAs and their specific proteins (U1 and U2 versus U11/U12). Unlike $\mathrm{U} 1$ and $\mathrm{U} 2$ in the major spliceosome, U11 and U12 form a stable di-snRNP, even in the absence of the pre-mRNA (Frilander and Steitz 1999; Will et al. 2004). While the Sm proteins and the multicomponent splicing factor SF3b are present both in the major $\mathrm{U} 1$ and U2 snRNPs and the minor U11/ U12 di-snRNP, seven proteins not found in U1 or U2, denoted $65 \mathrm{~K}, 59 \mathrm{~K}$, $48 \mathrm{~K}, 35 \mathrm{~K}, 31 \mathrm{~K}, 25 \mathrm{~K}$, and $20 \mathrm{~K}$, stably interact with the human U11/U12 disnRNP (Will et al. 2004). Interestingly, some of these U11/U12-specific proteins exhibit similarities to U1-specific proteins. The domain structure of the U1C protein, for example, is mirrored in the U11/U12 $20 \mathrm{~K}$ protein; the U11/U12-specific $35 \mathrm{~K}$ protein resembles the $\mathrm{U} 170 \mathrm{~K}$ protein and the organization of the U11/U12-65K protein is reminiscent of the $\mathrm{U} 1 \mathrm{~A}$ and $\mathrm{U}_{2} \mathrm{~B}^{\prime \prime}$ proteins (Benecke et al. 2005). These U11/U12-specific proteins may, therefore, functionally replace the respective U1- or U2-specific proteins in the minor spliceosome.

RNA recognition motifs (RRMs) constitute one of the most versatile macromolecular interaction modules, which can support RNA or protein binding by using diverse interaction surfaces (Maris et al. 2005). Spliceosomes make ample use of these multipurpose interaction modules. For example, the U11/U12-65K protein serves as a bridging factor between the U11 and U12 snRNPs (Benecke et al. 2005). It contains two RRMs connected by a linker that includes a proline-rich region. U11/U12-65K binds to the U11-associated $59 \mathrm{~K}$ protein via its $\mathrm{N}$-terminal half and to hairpin III of U12 snRNA using its C-terminal RRM (65K-cRRM) (Benecke et al. 2005). 65K-cRRM exhibits high-sequence similarity to the N-terminal RNA recognition motifs of the $\mathrm{U} 1 \mathrm{~A}$ and $\mathrm{U}^{2} \mathrm{~B}^{\prime \prime}$ proteins (U1A-nRRM, U2B" ${ }^{\prime \prime}$ nRRM) (Fig. 1A), suggesting that the three RRMs have evolved from a common ancestor by gene duplication and subsequent diversification (Bandziulis et al. 1989; Benecke et al. 2005).

The homology of the 65K-cRRM and the U1A/U2B" nRRMs is paralleled by the similarity of their RNA targets (Fig. 1B). Human 65K-cRRM has been shown to bind to nucleotides $109-125$ at the $3^{\prime}$-end of U12 snRNA, which forms hairpin III comprising a 5-base-pair (bp) stem and a 7-nucleotide (nt) loop (Benecke et al. 2005). The U1A and U2B" ${ }^{\prime \prime}$ RRRMs bind to the U1 snRNA hairpin II and the U2 snRNA hairpin IV, respectively, which exhibit similar global structures, but different sequences (Fig. 1B). Here, we have analyzed the RNA-binding determinants in human 65K-cRRM. Guided by the comparison of our crystal structure of an expanded 65K-cRRM with the U1A and $\mathrm{U}_{2} \mathrm{~B}^{\prime \prime}$-nRRMs, we introduced mutations and tested their effects on RNA binding in electrophoretic mobility shift assays (EMSA). Our results reveal that 65K-cRRM employs the same structural elements for RNA binding as the U1A and U2B" ${ }^{\prime \prime}$ nRRMs. A unique feature of the $65 \mathrm{~K}$ cRRM is an N-terminal expansion that apparently forms an integral element of the overall fold. Consistent with this noncanonical architecture, thermal unfolding and RNAbinding experiments suggested that the N-terminal expansion lends stability to the otherwise marginally stable $65 \mathrm{~K}$-cRRM structure, which, in turn, bestows the protein with the capacity to stably interact with its target RNA.

\section{RESULTS AND DISCUSSION}

\section{The core of the U11/U12-65K C-terminal RRM fails to bind RNA}

RRMs are about 80-90 amino acids in length and adopt an $\alpha / \beta$-sandwich structure. The minimal domain comprises 
four $\beta$-strands that form an anti-parallel $\beta$-sheet in the spatial order $\beta 4-\beta 1$ $\beta 3-\beta 2$ with two $\alpha$-helices packed against one face of the sheet. In many cases an additional $\beta$-hairpin structure (comprising $\beta 3^{\prime}$ and $\beta 3^{\prime \prime}$ ) is interspersed between strands $\beta 3$ and $\beta 4$. Canonical RRMs bind single-stranded RNA regions by splaying them out across their $\beta$-sheet surface. Two highly conserved sequence motifs, RNP1 and RNP2, located on the central strands $\beta 3$ and $\beta 1$, respectively, comprise aromatic residues that interact with the nucleic acid bases to build up an "intermolecular hydrophobic core" (Kranz and Hall 1999). Additionally, these residues participate in intramolecular interaction networks, which ensure proper orientation of other parts of the domain (Kranz and Hall 1998, 1999). Loop regions neighboring the $\beta$-sheet confer specificity for a particular RNA ligand (Scherly et al. 1990a; Allain et al. 1997; De Guzman et al. 1998; Maris et al. 2005). More recently, a number of RRMs and RRM-related proteins have been shown to bind RNA also by other strategies (Maris et al. 2005; Dominguez and Allain 2006; Skrisovska et al. 2007; Clery et al. 2008).

In the U11/U12-65K protein of the minor spliceosome, a fragment encompassing residues $380-517\left(65 \mathrm{~K}^{380-517}\right)$ was found to bind stem-loop III of the U12 snRNA (Benecke et al. 2005). RNA loop nucleotides and the loop-closing base pair, as well as the presence of a stemstructure, were shown to be required for binding by $65 \mathrm{~K}$ cRRM (Benecke et al. 2005). It remained unclear, however, which protein elements were involved in the binding of the RNA. $65 \mathrm{~K}^{380-517}$ contains the $65 \mathrm{~K}-\mathrm{cRRM}$ and additional sequences at both termini. In order to further explore the RNA-binding characteristics of 65K-cRRM and compare them with the homologous U1A-nRRM and $\mathrm{U}_{2} \mathrm{~B}^{\prime \prime}-\mathrm{nRRM}$, we generated a protein fragment, $65 \mathrm{~K}^{411-505}$, which encompasses the predicted core RRM fold, but lacks the terminal expansions. Using gel-shift assays, we tested the binding of a N-terminal GST fusion of $65 \mathrm{~K}^{411-505}$ to a RNA oligomer comprising U12 snRNA residues 109-125 (stem-loop III) (Fig. 1B), which was also used in previous interaction studies with $65 \mathrm{~K}^{380-517}$ (Benecke et al. 2005). Surprisingly, we failed to detect any binding of the shortened $65 \mathrm{~K}^{411-505}$ variant to the U12 stem-loop III oligo (Fig. 2, lanes 9-15).

$65 \mathrm{~K}^{411-505}$ lacks 31 residues at the $\mathrm{N}$ terminus and 11 residues at the $\mathrm{C}$ terminus compared with the expanded $65 \mathrm{~K}^{380-517}$. We next tested which of these tails facilitates RNA binding. A N-terminal GST fusion of $65 \mathrm{~K}^{380-506}$ encompassing the core RRM plus the N-terminal expansion efficiently bound the U12 stem-loop III oligo with an apparent $K_{\mathrm{d}}$ of $\sim 9 \mu \mathrm{M}$ (Fig. 2, lanes 16-22). The C-terminal appendix, additionally contained in fragment $65 \mathrm{~K}^{380-517}$, failed to further enhance RNA binding (Fig. 2, lanes 1-8). Instead, the C-terminal tail exerted a slight inhibitory effect; $65 \mathrm{~K}^{380-517}$ bound the RNA with an apparent $K_{\mathrm{d}}$ of around $16 \mu \mathrm{M}$ (after removal of the tag, we measured an apparent $K_{\mathrm{d}}$ of $\sim 11 \mu \mathrm{M}$, comparable to the value reported previously) (Benecke et al. 2005). This inhibitory effect of the C-terminal tail is reminiscent of a number of other RRMs, in which residues C-terminal of the anti-parallel $\beta$-sheet fold as a short $\alpha$-helix that partially occupies the RNA-binding site (Avis et al. 1996). Taken together, these results demonstrate that some 30 residues $\mathrm{N}$-terminal of the $65 \mathrm{~K}$-cRRM core are necessary for stable interaction with U12 stemloop III.

\section{The crystal structure of $65 K^{380-517}$ reveals a N-terminal clamp}

Previous studies of RRM-containing proteins failed to detect a requirement for an analogous $\mathrm{N}$-terminal expansion for RNA binding. Among 65K proteins from different species, however, the 30 residues preceding the C-terminal RRM core are highly conserved (for example, the human and Xenopus laevis $65 \mathrm{~K}$ proteins exhibit $68 \%$ sequence identity in that region) (Benecke et al. 2005). In order to explore the role of this structurally unique expansion for the function of the $65 \mathrm{~K}-\mathrm{cRRM}$, we determined the crystal structure of human $65 \mathrm{~K}^{380-517} .65 \mathrm{~K}^{380-517}$ was crystallized by the sitting drop vapor diffusion technique, yielding small needles with a reservoir comprising PEG3350 and $\mathrm{LiCl}$. The structure was solved by molecular replacement using the structure coordinates of U1A-nRRM (from PDB ID 1URN) (Oubridge et al. 1994) and refined at $2.5 \AA$ resolution. The final model exhibited $R_{\text {work }} / R_{\text {free }}$ factors of 19.4/25.2\% and maintained good stereochemistry 
TABLE 1. Crystallographic data and refinement

\begin{tabular}{|c|c|}
\hline Data collection & \\
\hline Wavelength $(\AA)$ & 0.984 \\
\hline Temperature (K) & 100 \\
\hline Space group & $\mathrm{C} 2$ \\
\hline \multicolumn{2}{|l|}{ Unit cell parameters $\left(\AA^{\circ}\right)^{\circ}$} \\
\hline $\mathrm{a}$ & 91.0 \\
\hline $\mathrm{b}$ & 33.5 \\
\hline c & 49.3 \\
\hline$\beta$ & 96.6 \\
\hline Resolution $(\AA)$ & $50.0-2.5(2.59-2.50)^{\mathrm{a}}$ \\
\hline \multicolumn{2}{|l|}{ Reflections } \\
\hline Unique & $5299(527)$ \\
\hline Completeness (\%) & $99.9(100.0)$ \\
\hline Redundancy & $3.5(3.3)$ \\
\hline $\mathrm{I} / \sigma(\mathrm{I})$ & $9.6(2.2)$ \\
\hline$R_{\mathrm{sym}}(\mathrm{I})$ & $10.8(56.3)$ \\
\hline \multicolumn{2}{|l|}{ Refinement } \\
\hline Resolution $(\AA)$ & $30.0-2.5(2.56-2.50)^{\mathrm{a}}$ \\
\hline \multicolumn{2}{|l|}{ Reflections } \\
\hline Number & 5283 \\
\hline Completeness (\%) & $99.7(99.5)$ \\
\hline Test set $(\%)$ & 10.7 \\
\hline$R_{\text {work }}{ }^{\mathrm{c}}$ & $19.4(23.6)$ \\
\hline$R_{\text {free }}{ }^{\mathrm{c}}$ & $25.2(35.8)$ \\
\hline $\mathrm{ESU}(\AA)^{\mathrm{d}}$ & 0.184 \\
\hline \multicolumn{2}{|l|}{ Contents of the asymmetric unit } \\
\hline Protein molecules/residues/atoms & 1/120/982 \\
\hline Water oxygens & 84 \\
\hline \multicolumn{2}{|l|}{ Mean B-factors $\left(\AA^{2}\right)$} \\
\hline Wilson & 33.8 \\
\hline Protein & 32.8 \\
\hline Water & 34.6 \\
\hline \multicolumn{2}{|l|}{ Ramachandran plot $(\%)$} \\
\hline Preferred & 96.6 \\
\hline Allowed & 3.4 \\
\hline Disallowed & 0 \\
\hline \multicolumn{2}{|l|}{ RMSD $^{f}$ from target geometry } \\
\hline Bond lengths $(\AA)$ & 0.008 \\
\hline Bond angles $\left({ }^{\circ}\right)$ & 1.18 \\
\hline \multicolumn{2}{|l|}{ RMSD B-factors $\left(\AA^{2}\right)$} \\
\hline Main chain bonds & 0.40 \\
\hline Main chain angles & 0.65 \\
\hline Side chain bonds & 1.12 \\
\hline Side chain angles & 1.90 \\
\hline PDB ID & $3 \mathrm{EGN}$ \\
\hline
\end{tabular}

${ }^{a}$ Data for the highest resolution shell in parentheses.

${ }^{\mathrm{b}} R_{\text {sym }}(I)=\Sigma_{\mathrm{hkl}} \Sigma_{\mathrm{i}}\left|l_{\mathrm{i}}(\mathrm{hkl})-<l(\mathrm{hkl})>\right| / \Sigma_{\mathrm{hkl}} \Sigma_{\mathrm{i}}\left|l_{\mathrm{i}}(\mathrm{hkl})\right|$; for $n$ independent reflections and $i$ observations of a given reflection; $\langle l(\mathrm{hkl})\rangle$, average intensity of the $i$ observations.

${ }^{\mathrm{c}} R=\Sigma_{\text {hkl }}|| F_{\text {obs }}|-| F_{\text {calc }}|| \Sigma_{\text {hkl }}\left|F_{\text {obs }}\right| ; R_{\text {work }}-\mathrm{hkl} \notin \mathrm{T} ; R_{\text {free }}-\mathrm{hkl} \in \mathrm{T} ; \mathrm{T}$ test set.

${ }^{d}($ ESU) Estimated overall coordinate error based on maximum likelihood.

${ }^{e}$ Calculated with Molprobity (http://molprobity.biochem.duke.edu/). f(RMSD) Root-mean-square deviation.

(Table 1). Residues 387-506 could be unequivocally traced in the electron density of the protein (Fig. 3A).

In agreement with domain prediction algorithms (de Castro et al. 2006; Letunic et al. 2006), residues 417-501 comprise an archetypal core RRM fold. The minimal motif is augmented by an $\alpha$-helical insertion (residues 449-454; helix $\alpha 1^{\prime}$ ) after the first $\alpha$-helix (Fig. 3A, cyan). Residues C-terminal of the core RRM lack regular secondary structure and are disordered beyond residue 506. The ordered portion of the C-terminal tail runs along one edge of the $\beta$-sheet and covers a peripheral portion of the $\beta$-sheet surface (Fig. 3A, black).

The amino acids comprising the $\mathrm{N}$-terminal expansion form two short $\alpha$-helices (Fig. 3A, helices $\alpha \mathrm{A}, \alpha \mathrm{B}$ ), one $3_{10^{-}}$ helix (Fig. $3 \mathrm{~A}, 3_{10} \mathrm{~A}$ ), and a long loop. These elements run along one side of the $\beta$-sheet and reach around to the opposite $\alpha$-helical side of the core RRM like a clamp (Fig. $3 \mathrm{~A})$. The $\mathrm{N}$-terminal expansion appears to be stably fastened to the core RRM by extensive hydrophobic interactions and additional hydrogen bonds (Fig. 3B). Overall, $1766 \mathrm{~A}^{2}$ of combined surface area are covered between the core RRM and the N-terminal expansion (residues 387417). Thus, the structure suggests that the additional elements are an integral part of the domain fold. A search for structural homologs using the DALI server (Holm and Sander 1993) did not reveal any other known RRM structure with a similar N-terminal appendix.

\section{K C-terminal RRM employs canonical motifs to bind RNA}

Since part of the N-terminal expansion of $65 \mathrm{~K}^{380-517}$ is neighboring the canonical RNA-binding $\beta$-sheet surface (Fig. 4A), it is conceivable that the $\mathrm{N}$ terminus is directly involved in RNA binding by the 65K-cRRM. Alternatively, it may play primarily a role in the structural integrity of the protein. To distinguish between these possibilities, we first asked whether the $65 \mathrm{~K}$-cRRM employs the canonical RRM structural elements for RNA binding. In U1A-nRRM, mutational and structural studies have revealed residues and regions that are critical for RNA binding (Nagai et al. 1990; Jessen et al. 1991; Oubridge et al. 1994). We therefore identified analogous residues in 65K-cRRM based on our structure-based sequence alignment (Fig. 1A), introduced the corresponding mutations, and tested RNA binding of the mutant proteins by EMSA.

In U1A-nRRM, mutations of aromatic residues on the $\beta$-sheet in RNP1 and RNP2 exert a large effect on RNA binding (Nagai et al. 1990; Jessen et al. 1991). Tyr423 from RNP2 of 65K-cRRM corresponds to the essential Tyr13 of U1A (Figs. 1A, 4A). Even the conservative mutation Tyr13Phe abolished RNA binding of U1A-nRRM entirely (Oubridge et al. 1994). We therefore converted Tyr423 of $65 \mathrm{~K}^{380-517}$ to an alanine and a phenylalanine and tested RNA binding of the mutant proteins. In complete analogy to the U1A-nRRM, both mutations essentially abolished binding to the U12 stem-loop III (Fig. 4B, cf. lanes 1-7 and lanes $8-14)$. These results confirm that the $\beta$-sheet surface of $65 \mathrm{~K}-\mathrm{cRRM}$ is involved in RNA binding. 

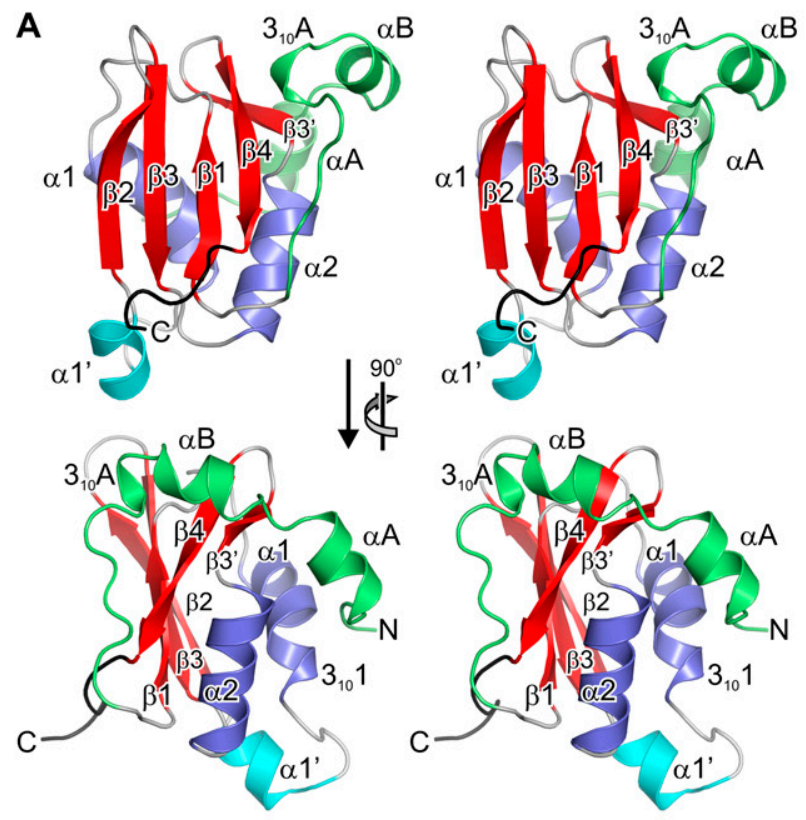

B
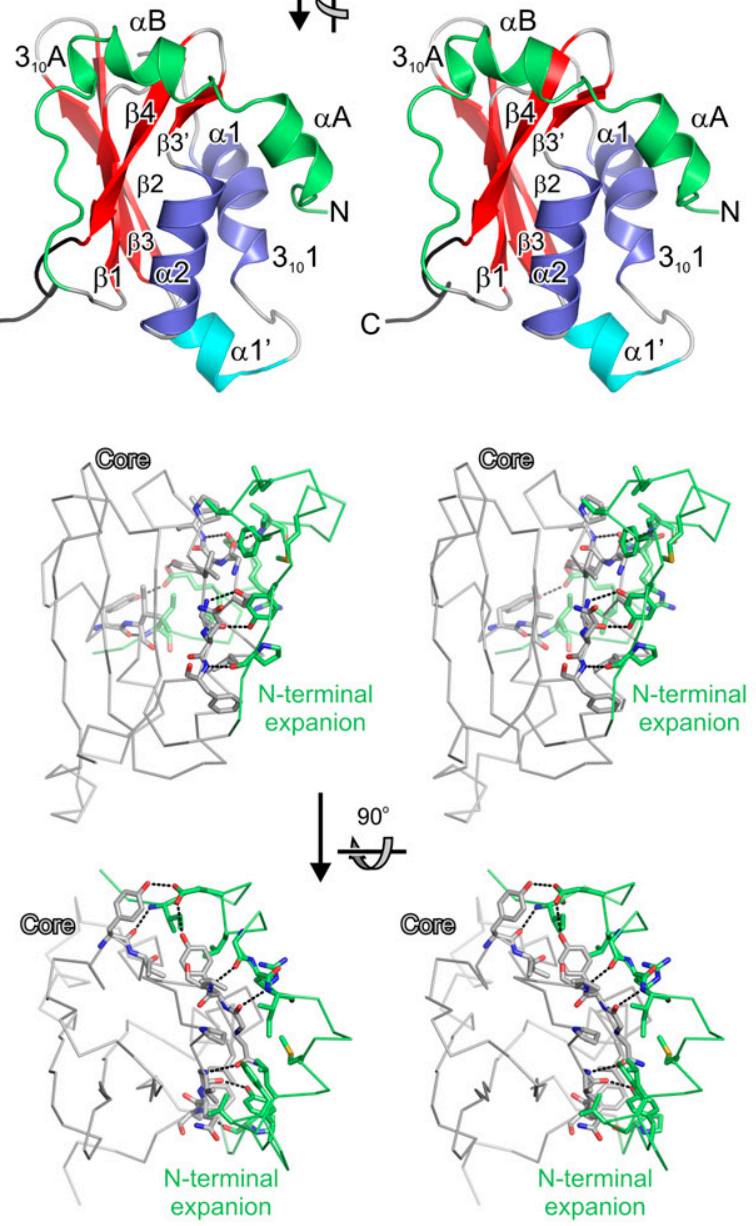

FIGURE 3. Structure of $65 \mathrm{~K}^{380-517}$. (A) Stereo ribbon plot of the expanded 65K-cRRM. (Top) Front view; (bottom) side view. Relative orientations are indicated. Secondary structure elements and termini are labeled. $\alpha$-helices, blue; $\beta$-strands, red. An additional $\alpha$-helix $\left(\alpha 1^{\prime}\right)$ in $65 \mathrm{~K}^{380-517}$ is shown in cyan. The N-terminal expansion $(380-417)$ is in green. The inset shows the N-terminal RRM of U1A (Nagai et al. 1990) in the same orientation for comparison. (B) Stereo plot illustrating the interaction of the $\mathrm{N}$-terminal expansion (green) with the RRM core (gray). (Top) Front view as in the top of $A$; (bottom) top view. Relative orientations are indicated. Interacting side chains are shown as sticks and color coded by atom type. Carbon, as the respective fragments; nitrogen, blue; oxygen, red; sulfur, yellow. Dashed lines indicate hydrogen bonds, most of which involve backbone functionalities.

In many RRMs, less-conserved residues located primarily in loops of variable length that connect the $\beta$-strands are responsible for sequence-specific recognition of the RNA targets (Scherly et al. 1990a; Allain et al. 1997; De Guzman et al. 1998). As shown for U1A and U2B"'-nRRMs, the loop

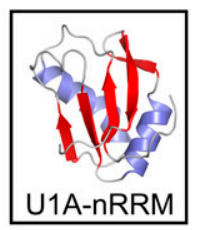

between strands $\beta 2$ and $\beta 3$ protrudes through the RNA loop and aids in splaying out the single-stranded portion of the RNA. A number of positively charged residues in this loop contact the phosphodiester backbone or the bases of the RNA. In U1A, mutation of Lys50 in the $\beta 2-\beta 3$ loop to a glutamine leads to a 10 - to 50 -fold reduction in RNA affinity (Nagai et al. 1990; Oubridge et al. 1994). Lys50 is conservatively replaced by $\operatorname{Arg} 464$ in $65 \mathrm{~K}$ cRRM (Figs. 1A, 4A). We mutated Arg464 to a glutamine and observed a $\sim 30$-fold reduction in the apparent $K_{\mathrm{d}}$ determined by EMSA (Fig. 4B, lanes 15-21).

Arg52 in the $\beta 2-\beta 3$ loop of U1A interacts with the RNA loop-closing base pair in a sequence-specific manner. Upon mutation to a glutamine, RNA affinity of U1A-nRRM is lost, while the more conservative replacement with a lysine retains partial RNA binding (Nagai et al. 1990; Oubridge et al. 1994). In 65K-cRRM, Arg52 is replaced by Lys466 (Figs. 1A, 4A). We tested the function of Lys466 in 65K-cRRM by introducing a glutamine at this position. Analogous to the situation in U1A, the Lys466Gln mutation entirely abrogated RNA binding, as monitored by gel shifts (Fig. 4B, lanes 22-28).

The $\beta 2-\beta 3$ loop in $65 \mathrm{~K}-\mathrm{cRRM}$ is shorter (six residues) than the corresponding loops in U1A or U2B" (nine residues). However, it has been shown that the length of this loop varies according to the size of the loop of the RNA ligand (Katsamba et al. 2002). Consistently, the RNA target of $65 \mathrm{~K}-\mathrm{cRRM}$ exhibits a correspondingly shorter loop (7 nt) compared with the RNA targets of U1A and U2B" ${ }^{\prime \prime}$ nRRMs (10 nt) (Fig. 1B). We conclude that similar to the situation in U1A and U2B"-nRRMs, the RNA-binding activity of the $\beta 2-\beta 3$ loop of $65 \mathrm{~K}$-cRRM is involved in RNA binding.

Taken together, the above data suggest that $65 \mathrm{~K}$-cRRM binds hairpin III of U12 snRNA via structural elements that are also employed by canonical RRMs, such as U1A-nRRM, for RNA binding (i.e., the $\beta$-sheet surface and the $\beta 2-\beta 3$ loop). However, we cannot exclude the possibility that the RNA comes to lie on these 
elements in a different orientation as, for example, in U1A-nRRM, and additional regions of $65 \mathrm{~K}$-cRRM may contribute to RNA binding. Novel modes of RNA binding have recently been observed in a number of noncanonical RRMs (for a recent review, see Clery et al. 2008).

Notably, the overall RNA-affinity of $65 \mathrm{~K}$-cRRM (which lies in the micromolar range) is significantly lower than the affinity of U1A-nRRM to its cognate RNA (which is in the nanomolar range) (Nagai et al. 1990; Hall and Stump 1992; Katsamba et al. 2002). Presently, we cannot pinpoint the exact source for this differential affinity. Most likely it arises from a number of changes on both the protein and the RNA.

\section{The $\mathrm{N}$-terminal expansion influences RNA binding primarily by stabilizing the fold of the core RRM}

To test whether the N-terminus directly participates in RNA binding, potential RNA-contacting residues were mutated, and the mutants were tested in gel-shift assays. In the $65 \mathrm{~K}^{380-517}$ structure, part of the N-terminal expansion borders the canonical RNA-binding surface (Fig. 4A). In particular, Val409 and Arg411 from the $\mathrm{N}$-terminal extension may approach an RNA ligand and foster direct contacts (Fig. 4A). We separately mutated Val409 to alanine and Arg411 to glutamine. Both mutations caused a small decrease in RNA affinity (apparent $K_{\mathrm{d}}$ 's of the GST-fusion proteins were estimated at $\sim 50$ and $\sim 30 \mu \mathrm{M}$, respectively). The moderate effects on RNA binding suggest that some residues in the $\mathrm{N}$-terminal extension may directly contact the RNA ligand. However, the putative contact points do not appear to be essential.

We next asked whether the $\mathrm{N}$-terminal expansion is important for the overall stability of the domain. Using a fluorescence-based thermal melting assay (Semisotnov et al. 1991), we compared the stabilities of $65 \mathrm{~K}-\mathrm{cRRM}$ constructs including $\left(65 \mathrm{~K}^{380-517}\right.$ and $\left.65 \mathrm{~K}^{380-506}\right)$ or lacking $\left(65 \mathrm{~K}^{411-505}\right)$ the $\mathrm{N}$-terminal
A

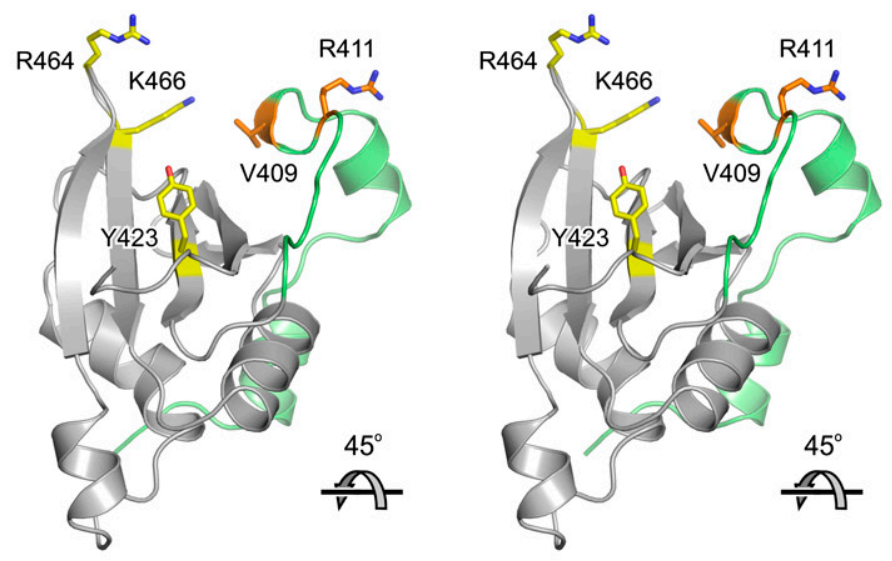

B
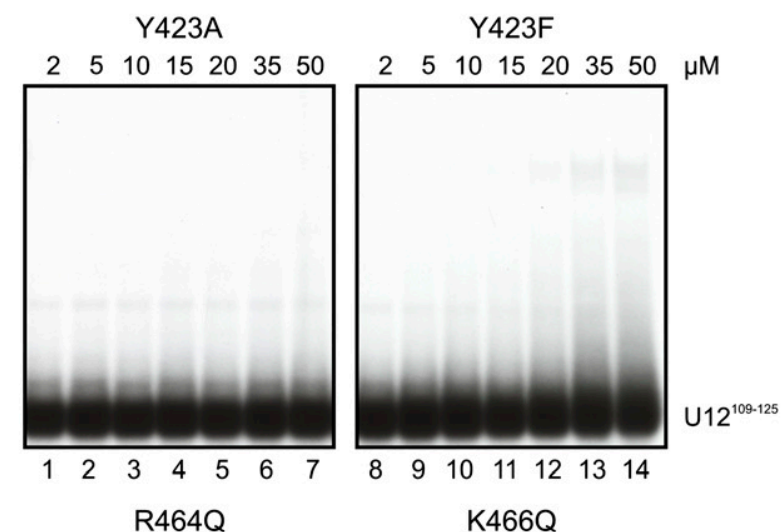

$\begin{array}{lllllll}2 & 5 & 10 & 15 & 20 & 35 & 50\end{array}$
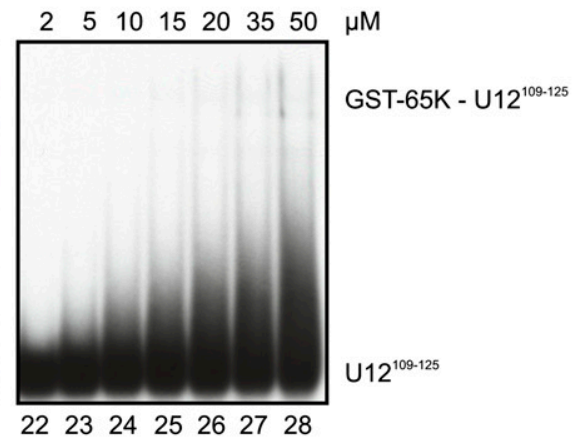

$\begin{array}{lllllll}15 & 16 & 17 & 18 & 19 & 20 & 21\end{array}$

R411Q
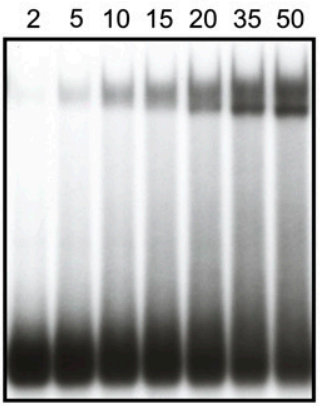

$\begin{array}{lllllll}29 & 30 & 31 & 32 & 33 & 34 & 35\end{array}$

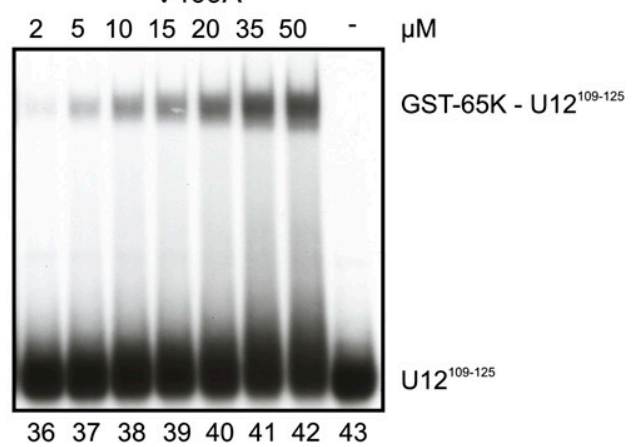

FIGURE 4. (Legend on next page) 


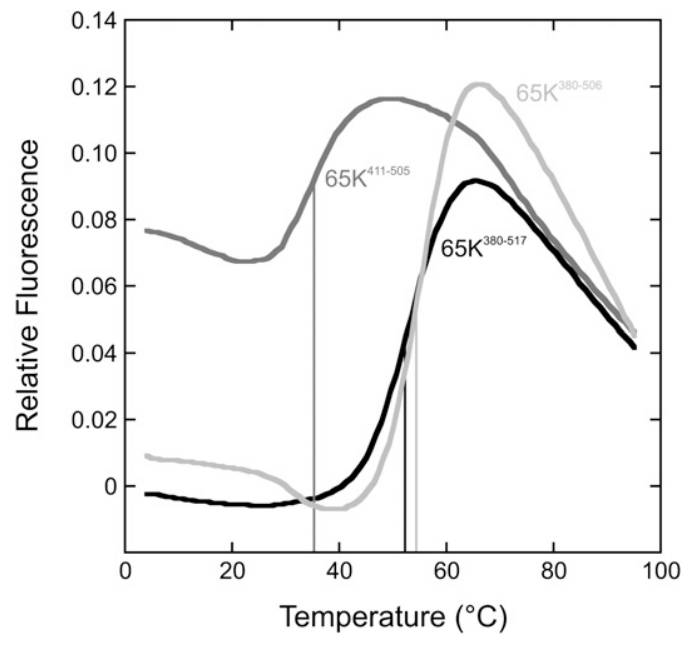

FIGURE 5. Fluorimetric melting analysis. Melting profiles of $65 \mathrm{~K}^{411-505}$ (gray curve), $65 \mathrm{~K}^{380-506}$ (light gray curve), and $65 \mathrm{~K}^{380-517}$ (black curve). The curves were obtained by heating protein samples in the presence of SYPRO Orange and monitoring the fluorescence of the dye. Melting temperatures, indicated by vertical lines, were taken as the midpoints of the cooperative transitions.

expansion (Fig. 5). 65 $\mathrm{K}^{380-517}$ and $65 \mathrm{~K}^{380-506}$ exhibited melting temperatures $\left(\mathrm{T}_{\mathrm{m}}\right)$ of $52^{\circ} \mathrm{C}$ and $54^{\circ} \mathrm{C}$, respectively. In sharp contrast, $65 \mathrm{~K}^{411-505}$, lacking the $\mathrm{N}$-terminal expansion, melted with a $\mathrm{T}_{\mathrm{m}}$ of $36^{\circ} \mathrm{C}$. Furthermore, the initial fluorescence of the $65 \mathrm{~K}^{411-505}$ sample was significantly higher than that of $65 \mathrm{~K}^{380-506}$ or $65 \mathrm{~K}^{380-517}$, suggesting that the integrity of its hydrophobic core was corrupted already at lower temperatures. These data show that the $\mathrm{N}$-terminal tail strongly stabilizes the core RRM. We suggest that this stabilization is important for RNA binding by supporting the appropriate folding and orientation of RNA-binding elements.

\section{Outlook: Modifying protein function by domain expansions}

Disorder predictions (Linding et al. 2003; Dosztanyi et al. 2005; Prilusky et al. 2005) suggest that the N-terminal expansion of the $65 \mathrm{~K}-\mathrm{cRRM}$ is intrinsically unstructured. regions in proteins undergo disorder-to-order transitions upon binding to an interaction partner such as another protein or a nucleic acid ligand (Wright and Dyson 1999). The N-terminal expansion of the 65K-cRRM seems to Natively unfolded proteins or intrinsically unstructured

behave intramolecularly in an analogous fashion. Upon binding to the core domain, it adopts a regular secondary structure.

Recently, the structures of predicted domains in some other spliceosomal proteins were investigated and similar expansions that confer stability on the core domains or safeguard the domains against aggregation have been found (Pena et al. 2007; Zhang et al. 2007). Reminiscent of the present case, these sequence additions are stably grafted onto the protein cores and have apparently become integral elements of the protein folds. For example, the Pmllp protein of the pre-mRNA retention and splicing complex (RES) exhibits a forkhead-associated (FHA) domain in its C-terminal half, while the N-terminal portion is intrinsically unstructured on its own (Trowitzsch et al. 2008). However, in the crystal structure (Trowitzsch et al. 2009), a portion of this $\mathrm{N}$ terminus is fixed on one flank of the FHA domain, and deletion of this tail dramatically reduces the solubility of the protein. In another example, a Jab1/MPN domain in the C-terminal region of the large Prp8 protein was found to be augmented by a number of internal insertions and terminal appendices (Pena et al. 2007; Zhang et al. 2007). These additional elements again exhibited stabilizing effects on the core domain. In addition, they endowed the core fold with novel protein-protein interaction capabilities (Pena et al. 2007; Zhang et al. 2007). It remains to be seen whether the $\mathrm{N}$-terminal appendix of the $65 \mathrm{~K}-\mathrm{cRRM}$ also bestows novel functions on the protein. Similar to the Prp8 case, it may facilitate protein-protein interactions, or it may be involved in fine tuning or regulation of RNA binding.

Interestingly, the RNA affinity and the specificity of the nRRM of U2B" are increased by formation of a complex with U2A' (Scherly et al. 1990a,b). Structural analysis has shown that $\mathrm{U}_{2} \mathrm{~A}^{\prime}$ binds to the side opposite the $\beta$-sheet surface of U2B" and fosters some distal, auxiliary RNA contacts (Price et al. 1998). Thus, the role of U2A' in supporting $\mathrm{U}^{2} \mathrm{~B}^{\prime \prime}$ in trans resembles the function of the $\mathrm{N}$-terminal expansion of U11/U12-65K cRRM in cis.

\section{MATERIALS AND METHODS}

\section{Cloning and expression}

A DNA fragment encoding human $65 \mathrm{~K}^{380-517}$ was PCR-amplified and cloned into pGEX-6p-1 (GE Healthcare) using BamHI and XhoI restriction sites. Mutagenesis was performed according to the QuikChange protocol (Stratagene). DNA primers were obtained from MWG Biotech.

FIGURE 4. Mutational analysis of $65 \mathrm{~K}^{380-517}$. (A) Stereo ribbon plot of $65 \mathrm{~K}^{380-517}$ with the RRM core region in gray and the $\mathrm{N}$-terminal expansion in green. Mutated residues (labeled) are shown as sticks and color coded by atom type. Carbons of mutated residues in the RRM core, yellow; carbons of mutated residues in the N-terminal expansion, orange. The view relative to Figure $2 \mathrm{~A}$ is indicated. $(B)$ Electrophoretic mobility-shift assays monitoring binding of U12 snRNA residues $109-125$ (stem-loop III) to GST fusions of $65 \mathrm{~K}^{380-517}$ mutants. Panels are labeled by the mutants used in the assays. The concentrations of the respective protein used are indicated above each lane.
For expression, a single colony of transformed E. coli Rosetta 2 (DE3) cells was used to inoculate $60 \mathrm{~mL}$ of $\mathrm{LB}$ medium supplemented with $100 \mu \mathrm{M}$ Ampicillin and $34 \mu \mathrm{M}$ Chloramphenicol and incubated overnight at $37^{\circ} \mathrm{C}$. Cells were harvested and used to 
inoculate $6 \mathrm{~L}$ of auto-inducing medium (Studier 2005) containing antibiotics. The cultures were grown to an $\mathrm{OD}_{600}$ of 0.6 at $37^{\circ} \mathrm{C}$, cooled to $16^{\circ} \mathrm{C}$, and incubated until cessation of growth. Cells were pelleted and resuspended in phosphate-buffered saline ( $\mathrm{pH} 7.3), 2$ $\mathrm{mM}$ DTT (PBS buffer) supplemented with 1 tablet/30 mL Complete protease inhibitor (Roche).

\section{Protein purification}

Cells were ruptured by sonification, debris was removed by centrifugation, and the soluble fusion protein was captured on glutathione-Sepharose 4 FF beads (GE Healthcare) pre-swollen in PBS buffer. Beads were washed with PBS buffer and subsequently with $50 \mathrm{mM}$ Tris- $\mathrm{HCl}$ ( $\mathrm{pH} 7.5), 150 \mathrm{mM} \mathrm{NaCl}, 2 \mathrm{mM}$ DTT (buffer A). The fusion protein was eluted with buffer A plus $100 \mathrm{mM}$ reduced glutathione (Sigma-Aldrich). The GST-tag was removed by adding $1 / 40(\mathrm{mg} / \mathrm{mg})$ Prescission protease and incubating overnight at $4^{\circ} \mathrm{C}$. Soluble protein was applied on a heparin Sepharose column (GE Healthcare) and eluted using a salt gradient from $150 \mathrm{mM}$ to $1 \mathrm{M} \mathrm{NaCl}$ in buffer A. Peak fractions were pooled and subjected to gel-filtration on a Superdex $7526 / 60$ column (GE Healthcare) with $20 \mathrm{mM}$ Tris-HCl (pH 7.5), $150 \mathrm{mM}$ $\mathrm{NaCl}, 2 \mathrm{mM}$ DTT (crystallization buffer). This strategy yielded $>98 \%$ pure protein as judged by SDS-PAGE analysis. The protein was concentrated to $28 \mathrm{mg} / \mathrm{mL}$ using a $5 \mathrm{kDa}$ MWCO concentrator (VIVAscience). Protein concentrations were determined via a Bradford assay (Bio-Rad).

\section{Crystallographic procedures}

We aimed at crystallizing 65K-cRRM in complex with RNA. Therefore, the protein was supplemented with $1.5 \mathrm{mM} \mathrm{MgCl}_{2}$ (buffer B) and incubated for $1 \mathrm{~h}$ with an RNA oligonucleotide mimicking hairpin III of U12 snRNA ( $5^{\prime}$-CCCGCCUACUUUGC GGG-3'). Crystals were grown by the sitting drop vapor diffusion technique with a reservoir containing 20\% (w/v) PEG3350 and $0.2 \mathrm{M} \mathrm{LiCl}$.

For diffraction data collection, crystals were transferred to mother liquor plus $15 \%(\mathrm{v} / \mathrm{v})$ propylene glycol and flash-frozen in liquid nitrogen. Data were collected at $100 \mathrm{~K}$ at the PXI beamline of SLS (Villigen) using a microfocused beam. Data were processed with the HKL2000 suite of programs (Otwinowski and Minor 1997).

Crystals belonged to space-group C2 and exhibited a solvent content of $47 \%$, assuming one $65 \mathrm{~K}$-cRRM molecule without RNA ligand per asymmetric unit. The structure was solved by molecular replacement with the program Molrep (Vagin and Teplyakov 2000) using the structure coordinates of the U1A-nRRM (from PDB ID 1URN) (Oubridge et al. 1994). Iterative cycles of manual model building in Coot (Emsley and Cowtan 2004) and automatic refinement using the programs Phenix (Adams et al. 2002) and REFMAC5 (Murshudov et al. 1997) yielded the final model (Table 1).

The structure factors and coordinates have been deposited in the Protein Data Bank (http://www.pdb.org) under entry code $3 \mathrm{EGN}$, and will be released upon publication.

\section{Electrophoretic mobility shift assays (EMSA)}

EMSA experiments were conducted in duplicates. A total of 0-300 pmol untagged protein were incubated in buffer B with 0.25 pmol of $\left[{ }^{32} \mathrm{P}\right]$-end-labeled RNA oligonucleotide (5'-CCCGCCUACUU UGCGGG-3'), $1 \mu \mathrm{L}$ of $10 \mathrm{mg} / \mathrm{mL}$ of $E$. coli tRNA, and $0.25 \mu \mathrm{L}$ of RNasin (Promega) in a final volume of $10 \mu \mathrm{L}$ for $45 \mathrm{~min}$ at $4^{\circ} \mathrm{C}$. After addition of $6 \mu \mathrm{L}$ of loading dye (50\% glycerol, $0.5 \times \mathrm{TBE}$ buffer), RNA-protein complexes were separated on a native $6 \%$ (29:1 acrylamide:bis-acrylamide) polyacrylamide gel at $8 \mathrm{~W}$ and $4^{\circ} \mathrm{C}$. For GST-tagged proteins, the same procedure was applied, but mixtures were incubated in 20 mM HEPES ( $\mathrm{pH} 7.9$ ), $1.5 \mathrm{mM}$ $\mathrm{MgCl}_{2}, 0.2 \mathrm{mM}$ EDTA, $200 \mathrm{mM} \mathrm{KCl}, 0.1 \%$ Triton X-100.

Bands were visualized by autoradiography. Quantification of the bands was performed with ImageQuant (GE Healthcare). Apparent $K_{\mathrm{d}}$-values were estimated from the protein concentrations required to elicit a $50 \%$ shift of the RNA.

\section{Thermal denaturation experiments}

A total of $18 \mu \mathrm{L}$ of purified proteins at $30 \mu \mathrm{M}$ concentration in 20 $\mathrm{mM} \mathrm{Na} / \mathrm{KPO}_{4}$ (pH 7.5), $1.5 \mathrm{mM} \mathrm{MgCl}, 150 \mathrm{mM} \mathrm{NaF}, 2 \mathrm{mM}$ DTT were mixed with $2 \mu \mathrm{L}$ of $5 \times$ SYPRO Orange (SigmaAldrich). The changes in fluorescence of the samples as a function of temperature $\left(4^{\circ} \mathrm{C}-95^{\circ} \mathrm{C}\right.$ in steps of $\left.1^{\circ} \mathrm{C} / \mathrm{min}\right)$ were monitored in a real-time PCR machine. The fluorescence was recorded once per degree with 30 -sec intervals between reads.

\section{ACKNOWLEDGMENTS}

We thank Reinhard Lührmann for generous support, Elke Penka for excellent technical assistance, the team at the beamline PXI (SLS, Villigen, Switzerland) for support during data collection, Cindy Will for critical reading of the manuscript, and members of our group for helpful discussions. This work was supported by a Ph.D. scholarship from the Boehringer Ingelheim Fonds (to C.N.) and the Max-Planck-Society (to M.C.W.).

Received September 11, 2008; accepted March 16, 2009.

\section{REFERENCES}

Adams PD, Grosse-Kunstleve RW, Hung LW, Ioerger TR, McCoy AJ, Moriarty NW, Read RJ, Sacchettini JC, Sauter NK, Terwilliger TC. 2002. PHENIX: Building new software for automated crystallographic structure determination. Acta Crystallogr D Biol Crystallogr 58: $1948-1954$.

Allain FH, Howe PW, Neuhaus D, Varani G. 1997. Structural basis of the RNA-binding specificity of human U1A protein. $E M B O J \mathbf{1 6}$ : 5764-5772.

Avis JM, Allain FH, Howe PW, Varani G, Nagai K, Neuhaus D. 1996. Solution structure of the N-terminal RNP domain of U1A protein: The role of C-terminal residues in structure stability and RNA binding. J Mol Biol 257: 398-411.

Bandziulis RJ, Swanson MS, Dreyfuss G. 1989. RNA-binding proteins as developmental regulators. Genes \& Dev 3: 431-437.

Benecke H, Lührmann R, Will CL. 2005. The U11/U12 snRNP 65K protein acts as a molecular bridge, binding the U12 snRNA and U11-59K protein. EMBO J 24: 3057-3069.

Brow DA. 2002. Allosteric cascade of spliceosome activation. Annu Rev Genet 36: 333-360.

Burge CB, Padgett RA, Sharp PA. 1998. Evolutionary fates and origins of U12-type introns. Mol Cell 2: 773-785.

Burge CB, Query CC, Sharp PA. 1999. Splicing of precursors to mRNAs by the spliceosomes. In: The RNA world, 2 nd ed. (eds. RF Gesteland et al.) pp 525-560. Cold Spring Harbor Laboratory Press, Cold Spring Harbor, NY. 
Clery A, Blatter M, Allain FH. 2008. RNA recognition motifs: Boring? Not quite. Curr Opin Struct Biol 18: 290-298.

de Castro E, Sigrist CJ, Gattiker A, Bulliard V, LangendijkGenevaux PS, Gasteiger E, Bairoch A, Hulo N. 2006. ScanProsite: Detection of PROSITE signature matches and ProRule-associated functional and structural residues in proteins. Nucleic Acids Res 34: W362-W365.

De Guzman RN, Turner RB, Summers MF. 1998. Protein-RNA recognition. Biopolymers 48: 181-195.

Dominguez C, Allain FH. 2006. NMR structure of the three quasi RNA recognition motifs (qRRMs) of human hnRNP $F$ and interaction studies with Bcl-x G-tract RNA: A novel mode of RNA recognition. Nucleic Acids Res 34: 3634-3645.

Dosztanyi Z, Csizmok V, Tompa P, Simon I. 2005. IUPred: Web server for the prediction of intrinsically unstructured regions of proteins based on estimated energy content. Bioinformatics 21: 3433-3434.

Emsley P, Cowtan K. 2004. Coot: Model-building tools for molecular graphics. Acta Crystallogr D Biol Crystallogr 60: 2126-2132.

Frilander MJ, Steitz JA. 1999. Initial recognition of U12-dependent introns requires both U11/5' splice-site and U12/branchpoint interactions. Genes \& Dev 13: 851-863.

Hall KB, Stump WT. 1992. Interaction of N-terminal domain of U1A protein with an RNA stem/loop. Nucleic Acids Res 20: 4283-4290.

Holm L, Sander C. 1993. Protein structure comparison by alignment of distance matrices. J Mol Biol 233: 123-138.

Jessen TH, Oubridge C, Teo CH, Pritchard C, Nagai K. 1991. Identification of molecular contacts between the U1 A small nuclear ribonucleoprotein and U1 RNA. EMBO J 10: 3447-3456.

Katsamba PS, Bayramyan M, Haworth IS, Myszka DG, LairdOffringa IA. 2002. Complex role of the $\beta 2-\beta 3$ loop in the interaction of U1A with U1 hairpin II RNA. J Biol Chem 277: 33267-33274.

Kranz JK, Hall KB. 1998. RNA binding mediates the local cooperativity between the $\beta$-sheet and the C-terminal tail of the human U1A RBD1 protein. J Mol Biol 275: 465-481.

Kranz JK, Hall KB. 1999. RNA recognition by the human U1A protein is mediated by a network of local cooperative interactions that create the optimal binding surface. J Mol Biol 285: 215-231.

Letunic I, Copley RR, Pils B, Pinkert S, Schultz J, Bork P. 2006. SMART 5: Domains in the context of genomes and networks. Nucleic Acids Res 34: D257-D260.

Levine A, Durbin R. 2001. A computational scan for U12-dependent introns in the human genome sequence. Nucleic Acids Res 29: 4006-4013.

Linding R, Jensen LJ, Diella F, Bork P, Gibson TJ, Russell RB. 2003. Protein disorder prediction: Implications for structural proteomics. Structure 11: 1453-1459.

Maris C, Dominguez C, Allain FH. 2005. The RNA recognition motif, a plastic RNA-binding platform to regulate post-transcriptional gene expression. FEBS J 272: 2118-2131.

Murshudov GN, Vagin AA, Dodson EJ. 1997. Refinement of macromolecular structures by the maximum-likelihood method. Acta Crystallogr D Biol Crystallogr 53: 240-255.

Nagai K, Oubridge C, Jessen TH, Li J, Evans PR. 1990. Crystal structure of the RNA-binding domain of the U1 small nuclear ribonucleoprotein A. Nature 348: 515-520.

Nilsen TW. 2003. The spliceosome: The most complex macromolecular machine in the cell? Bioessays 25: 1147-1149.

Otwinowski Z, Minor W. 1997. Processing of X-ray diffraction data collected in oscillation mode. Methods Enzymol 276: 307-326.

Oubridge C, Ito N, Evans PR, Teo CH, Nagai K. 1994. Crystal structure at 1.92 A resolution of the RNA-binding domain of the
U1A spliceosomal protein complexed with an RNA hairpin. Nature 372: 432-438.

Pena V, Liu S, Bujnicki JM, Lührmann R, Wahl MC. 2007. Structure of a multipartite protein-protein interaction domain in splicing factor prp8 and its link to retinitis pigmentosa. Mol Cell 25: 615624.

Price SR, Evans PR, Nagai K. 1998. Crystal structure of the spliceosomal $\mathrm{U}^{2} \mathrm{~B}^{\prime \prime}-\mathrm{U} 2 \mathrm{~A}^{\prime}$ protein complex bound to a fragment of U2 small nuclear RNA. Nature 394: 645-650.

Prilusky J, Felder CE, Zeev-Ben-Mordehai T, Rydberg EH, Man O, Beckmann JS, Silman I, Sussman JL. 2005. FoldIndex: A simple tool to predict whether a given protein sequence is intrinsically unfolded. Bioinformatics 21: 3435-3438.

Reed R, Palandjian L. 1997. Spliceosome assembly. In: Eukaryotic $m R N A$ processing (ed. AR Krainer), pp 103-129. IRL Press, Oxford, UK.

Scherly D, Boelens W, Dathan NA, van Venrooij WJ, Mattaj IW. 1990a. Major determinants of the specificity of interaction between small nuclear ribonucleoproteins U1A and $\mathrm{U}^{2} \mathrm{~B}^{\prime \prime}$ and their cognate RNAs. Nature 345: 502-506.

Scherly D, Dathan NA, Boelens W, van Venrooij WJ, Mattaj IW. 1990b. The U2B" RNP motif as a site of protein-protein interaction. EMBO J 9: 3675-3681.

Semisotnov GV, Rodionova NA, Razgulyaev OI, Uversky VN, Gripas AF, Gilmanshin RI. 1991. Study of the "molten globule" intermediate state in protein folding by a hydrophobic fluorescent probe. Biopolymers 31: 119-128.

Skrisovska L, Bourgeois CF, Stefl R, Grellscheid SN, Kister L, Wenter P, Elliott DJ, Stevenin J, Allain FH. 2007. The testisspecific human protein RBMY recognizes RNA through a novel mode of interaction. EMBO Rep 8: 372-379.

Studier FW. 2005. Protein production by auto-induction in high density shaking cultures. Protein Expr Purif 41: 207-234.

Trowitzsch S, Weber G, Lührmann R, Wahl MC. 2008. An unusual RNA recognition motif acts as a scaffold for multiple proteins in the pre-mRNA retention and splicing complex. J Biol Chem 283: 32317-32327.

Trowitzsch S, Weber G, Lührmann R, Wahl MC. 2009. Crystal structure of the Pmllp subunit of the yeast precursor mRNA retention and splicing complex. J Mol Biol 385: 531-541.

Vagin A, Teplyakov A. 2000. An approach to multi-copy search in molecular replacement. Acta Crystallogr D Biol Crystallogr 56: $1622-1624$.

Will CL, Lührmann R. 1997. snRNP structure and function. In: Eukaryotic mRNA processing (ed. AR Krainer), pp 130-173. IRL Press, Oxford, UK.

Will CL, Lührmann R. 2005. Splicing of a rare class of introns by the U12-dependent spliceosome. Biol Chem 386: 713-724.

Will CL, Lührmann R. 2006. Spliceosome structure and function. In: The RNA world, 3rd ed. (eds. RF Gesteland et al.), pp 369400. Cold Spring Harbor Laboratory Press, Cold Spring Harbor, NY.

Will CL, Schneider C, Hossbach M, Urlaub H, Rauhut R, Elbashir S, Tuschl T, Lührmann R. 2004. The human 18S U11/U12 snRNP contains a set of novel proteins not found in the U2-dependent spliceosome. RNA 10: 929-941.

Wright PE, Dyson HJ. 1999. Intrinsically unstructured proteins: Reassessing the protein structure-function paradigm. J Mol Biol 293: 321-331.

Zhang L, Shen J, Guarnieri MT, Heroux A, Yang K, Zhao R. 2007. Crystal structure of the C-terminal domain of splicing factor Prp8 carrying retinitis pigmentosa mutants. Protein Sci 16: 10241031. 

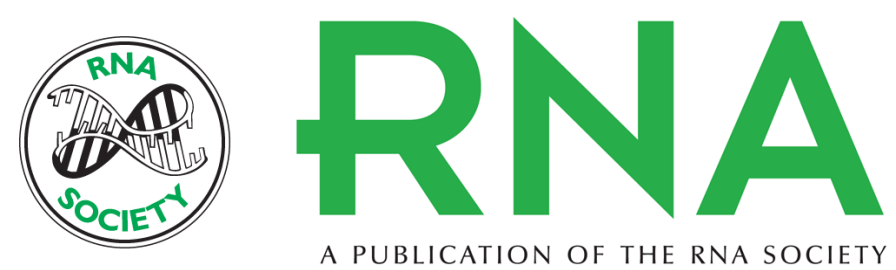

\section{Functional stabilization of an RNA recognition motif by a noncanonical $\mathrm{N}$-terminal expansion}

Catharina Netter, Gert Weber, Heike Benecke, et al.

RNA 2009 15: 1305-1313 originally published online May 15, 2009

Access the most recent version at doi:10.1261/rna.1359909

$\begin{array}{ll}\text { References } & \begin{array}{l}\text { This article cites } 44 \text { articles, } 7 \text { of which can be accessed free at: } \\ \text { http://rnajournal.cshlp.org/content/15/7/1305.full.html\#ref-list-1 }\end{array}\end{array}$

License

Email Alerting Receive free email alerts when new articles cite this article - sign up in the box at the Service top right corner of the article or click here. 